\title{
Then They Came for the Dogs!
}

\section{Simon Hallsworth}

\begin{abstract}
This paper examines the British state's desire to liquidate the Pit Bull as a breed. It examines the moral panic that brought the Pit Bull Terrier to public attention and traces the government's knee-jerk response that resulted in the Dangerous Dogs Act (1991), the legal instrument that mandated Britain's first attempt at canine genocide. Though public protection was the stated justification of this exercise in state violence, there was and is no evidence to support the case for canine killing through the indiscriminate blanket medium of breed specific legislation. Far from conceiving the dog an aggressor and humans its victims, this paper precedes on the assumption that the dogs are the victims and humans the inhuman aggressor. The paper concludes by examining the factors that provoked the UK's descent into mass dog killing.
\end{abstract}

This paper examines what has become one of the United Kingdom's ['UK'] key public enemies in the last 20 years. The enemy in question is not a member of a terrorist network or, indeed, a member of the banking fraternity that has brought the country to the verge of financial ruin. The enemy in question is a medium-sized dog. In the United States of America ['US'], where it was first bred in the $19^{\text {th }}$ century, the dog is known as the Pit Bull Terrier; in the UK, whose Kennel Club refuses to recognise the dog as a breed, it is legally defined as a 'pit bull type' and labelled a 'dangerous dog'. It is also referred to variously as a 'weapon dog', 'status dog' and 'dog from hell' by the mass media and, to evoke Cohen's terminology (Cohen 1972), various 'moral entrepreneurs and right thinking people'.

Since the late 1980s, when the Pit Bull first came to public attention, this canine has found itself the object of an official campaign that has as its stated aim the wholesale destruction of the Pit-Bull as a breed. Not to put too fine a point on it, Britain's very own attempt at a canine genocide. This is a campaign which, from the early 1990s, when the Dangerous Dogs Act was passed (the legislation which legitimated mass dog killing), would see approximately 1,000 of these dogs seized and killed (Kaspersson 2008); while those allowed to live under the subsequent revised Act (1997) are compulsorily neutered. As I write this paper, these dogs are still being seized and many are still being killed. Not, it must be emphasised, on the basis that they have bitten anyone, or indeed pose any risk to humans. Their death is rather justified on the fascistic principle of what they are. Like the Jews in Nazi Germany, the Pit Bulls' ultimate crime is that they have the wrong imputed characteristics and are associated with crimes not of their making.

\footnotetext{
1 The author would like to thank Maria Kaspersson, Ragnhild Sollund and the co-editors of this special issue for their helpful and incisive comments.
} 
Canine extermination is justified on the basis that 'breed specific' legislation would rid the country of a uniquely atavistic and violent predator that has no place in the British way of life (Baker 2007). This dog, it has been claimed, is essentially different from other 'respectable' members of the canine family. It is unstable and more violent and as such poses a real threat to anyone and everyone around it (Malthouse 2009). The British public are victims and it is in the name of public protection that the seizure and killing of these dogs is justified.

This paper presents an alternative and diametrically opposed interpretation. The Pit Bull Terrier is no villain, nor is British society the victim of this breed. The victim here is a dog that has found itself subject to a staggering degree of inhumanity on the part of society that has lost all moral bearings in relation to its relations with non-humans. This is not, in other words, the story of how a victimised society took the necessary steps to confront and tackle a real social problem. This is a sad story about violent, ill-informed and ignorant people who, on the basis of limited evidence (albeit a rich and disturbing fantasy life), elect to squander considerable social resources in pursuit of dog killing.

The paper begins by exploring how the Pit Bull first became an object of public attention. It explores the resulting moral panic, and then follows the path that would lead a government towards a legislative response that would mandate mass dog killing. The paper subsequently charts the changing response to the Pit Bull bringing the story up to the present where we face renewed calls to seize and destroy Pit Bulls along with other so called 'status dogs'.

As the paper will establish, there is no evidence to support the criminalisation and destruction of these dogs. Their construction as a public enemy owes more to an array of populist fantasies whipped up by an irresponsible media and law and order politicians than to any commitment to evidence. The paper concludes by examining why a society that claims to love 'man's best friend' came to embrace dog killing with such zeal and enthusiasm.

\section{Let's kill dogs!}

The original impetus and scene-setting events that would subsequently justify the criminalisation of the Pit Bull were three widely and sensationally reported dog attacks on humans that occurred between 1990 and 1991. The first involved a fatal attack on an eleven year old by two Rottweiler's in 1990, and this was followed by two non fatal dog attacks that were then attributed to Pit Bulls in 1991 (May 2001). This provided the evidential basis for what became a moral panic. Within a few months of these attacks, Pit Bulls and their working class owners became identified as a new folk devil confronting innocent communities across the UK (Jones, 2006).

Represented in demonic imagery through the medium of a deviancy amplification spiral, the dogs were presented in categories stressing their essential difference from the rest of the (respectable) canine world. Various inflammatory labels quickly became attached to 'Other' them, such as 'weapon dogs' and 'devil dogs'. What had been an entirely legitimate and popular breed in 
the US ${ }^{2}$ was conceded an array of monstrous qualities by an array of selfcertified experts. The jaws of the pit bull, it was argued, were far stronger than other breeds and when they grabbed their prey their jaws would - it was claimed - uniquely lock $^{3}$. Pit bulls were said to be far more aggressive than other breeds and possessed an unstable temperament that made them impossible to train. In his biography Kenneth Baker, the Home Secretary of the time and subsequent architect of the Dangerous Dogs Act, claimed he had been 'reliably informed' by an unnamed 'dog expert' that 'all Pit Bulls invariably go mad' (Baker 1993).

To these fears about psychotic dogs were conjoined various fears, phobias and anxieties about their owners who were represented as workshy, tattooed, dole scrounging products of the underclass; the sub-proletariat that were being blamed for just about every social evil in the UK by the right wing Conservative government of the day. Unlike the middle classes who owned their pedigree dogs for entirely benevolent reasons, dog ownership in the case of the Pit Bull was simply considered in terms analogous to weapon ownership. These were 'weapon dogs' used either for criminal purposes or as the means by which street gangsters could terrorise an innocent public. Conceived in this sense, the dogs were seen to violate what it was to be a loyal and faithful companion and, as such were no longer worthy of being considered as a pet but as a species of vermin. As Podberscek observes pets we love, but once constructed as vermin the Pit Bull was effectively positioned as an outsider, in effect matter out of place whose killing appeared justified just as it is in the case of other animals constructed as vermin (Podberscek 1994; see also Stephenson. 2008).

For a weak government tainted with sleaze and with ebbing electoral support, Kenneth Baker had no problem in relinquishing any sense of perspective and capitulated wholesale to the mass media and their rabid demand that the government act decisively on the 'dangerous dogs' issue. On the basis of no evidence at all being presented that attested to a social problem that required immediate legislative solutions; and on the basis of no evidence at all suggesting that the existing regulatory framework had failed, in 1991 Baker created (and in record time) what would become the Dangerous Dogs Act. This knee jerk legislation took no longer than six weeks to create and push through a parliament that, with bipartisan support, had no trouble voting it into law (legislation.gov.uk 1991) ${ }^{4}$.

What the Act did was to provide a legal mandate for the entire destruction of the Pit Bull breed (along with three other breeds). On the basis of the fascistic premise that you are what your genes have made you, the Pit Bull was to become subject to what would become the UK's very own attempt at engineering a canine genocide. For the sin of having the wrong parents, the Act allowed for all

\footnotetext{
2 The Pit Bull Terrier has a long and illustrious history in the US where its intelligence, loyalty, strength and tractability with humans established it as one of its most popular breeds throughout the twentieth century. 'In the first world war the breed was used to represent the US in artwork. Popular companies like RCA and the Buster Brown Shoe Company used the breed as their mascots. A Pit Bull named Petie starred in the popular children's television series, Our Gang; a Pit Bull mix named Stubby became a decorated WWI hero. Pit Bulls accompanied pioneer families on their explorations. Laura Ingalls Wilder of the popular Little House books owned a working Pit Bulldog named Jack. Famous individuals like Theodore Roosevelt and Helen Keller owned the breed' (Bulldog breeds.com 2010)

3 For some contemporary examples of this demonization process see Doward, J. (2007a, 2007b)

${ }^{4}$ See also Lodge's (2010) discussion around 'knee-jerk' policy making in relation to high profile dog incidents.
} 
Pit Bulls to be seized and destroyed. By reconstructing the dog as a 'type' defined by various physical characteristics, many other dogs which were not Pit Bulls (but with the misfortune to have a preponderance of Pit bull features) were also placed at risk of being killed. This was 'pre-emptive criminalisation' with a vengeance (Fitzgibbon 2004). Ownership was also criminalised as was breeding, advertising and selling such dogs. Those who contravened these terms faced a jail sentence of up to 6 months, a criminal record and a fine of up to $£ 5,000$.

Given that the Pit Bull was not recognised as a breed, the architects of the Act had to find a suitable label that would allow its features to be recognised by the enforcement agencies mandated to seize and kill them. Eventually they decided that the Pit Bull was not a breed but a canine 'type' and it was as a type that it would be destroyed. To help the process of identification the British state had no option but to use the breed description for the Pit Bull which had been developed many years earlier by the Kennel Club of the US.

The British police had no difficulty whatever in adapting to its role as establishment canine killers and dutifully went about the grisly task of seizing people's pets, typically healthy dogs that had bitten no one, which various vets had no trouble killing. Within five years of the Act being passed into law around 1,000 dogs were hunted down and executed (Kaspersson 2008).

As the moral panic literature attests, such phenomena by their nature do not last long (Cohen, 1972; Goode and Ben-Yehuda 1994). Eventually the issue attention cycle shifts as new categories of folk devil are identified while interest in the old one gradually diminishes. The public eventually forgot about the Pit Bulls in their midst. However, other problems surfaced. To begin with, the courts where seized dogs were to be condemned demonstrated a healthy reluctance to do so, particularly with family pets. A number of people were also beginning to wake up to the fact that the Dangerous Dogs Act was a poorly thought through, not to say draconian, instrument of regulation. Though the Kennel Club had refused and continues to refuse to recognise the Pit Bull as a legitimate breed, even this august body came to recognise that it was deed rather than breed that mattered. Though the RSPCA, a body ostensibly in the business of saving dogs from cruelty, originally helped the government frame the Dangerous dogs Act, it also joined the chorus of dissenting voices - while allowing every Pit Bull that fell into their hands to be destroyed.

Eventually, in 1997, in the face of growing opposition, Parliament revised what had become seen as a badly flawed piece of legislation (see Legislation.gov.uk (1997) for details). Proscribed dogs were still banned and ownership could still result in a criminal charge, only instead of simply killing every Pit Bull seized, the courts were now given discretion to determine whether a dog could be allowed to live and be returned to its owner - if, that is, the owner in question was deemed acceptable to the courts. Despite this act of seeming benevolence things were to become increasingly difficult for the Pit Bull. The Act mandated having any proscribed 'dangerous dog' seized and kept in kennels by the police; a deeply traumatic event both for the dogs and their owners. Owners were not allowed to know where their pets were being kept and the police had no obligation to notify them about their state of health and wellbeing. Instead of the state having to prove beyond reasonable doubt that the dog was guilty of a crime, the Act reversed the burden of proof and expected the owner to 
demonstrate beyond reasonable doubt that the dog was safe to the public - a near impossible task. This marked the eviction of what had hitherto been considered a sacred principle of British justice: innocent until proved guilty. All 'exempted' dogs were also required to be neutered, micro-chipped, kept on a lead and muzzled at all times in public places (including in cars), tattooed and kept on a public register for 'exempted dogs'. If this was not vindictive enough, 'exempted' dogs were not allowed to be cared for by anyone other than those named on the exempted dog index.

'As a dog returns to its vomit, so a fool returns to his stupidity' and so it came to pass that the principle architect of the Dangerous Dogs Act, Kenneth Baker, unhappy at such revision wrote an article for the Guardian newspaper in 2007, bemoaning what he termed the 'watering down' of the Act (Baker 2007). In the article he also went on to justify the 'success' of the Act on the absurd premise that there were many members of the public now alive who would otherwise have been mauled to death by the predominantly non-violent dogs his Act had consigned to death. He ignored the fact that the very small number of human fatalities caused by dogs each year did not change with the enforcement of the Dangerous Dogs Act.

Up to the early years of the new century fears about so called 'dangerous dogs' by and large diminished in the UK. The press did not spend that much time reporting the issue and the police did not actively enforce the Act. Within the last six years however, the press have again started to report cases involving so called 'dangerous dogs' using the same prejudicial language that accompanied their first exposé. What has made the reporting rather different this time round is that the dogs are now being conjoined with another contemporary moral panic; one that holds that organised American style gangs are now on the rise and bringing terror to the streets and estates of our fair cities (Hallsworth 2011). According to Acting Deputy Assistant Commissioner Steve Allen: "Pit Bull-type dogs had become a weapon of choice for gang members, drug dealers and street corner thugs" (BBC News 2006).

This narrative is now being mediated routinely through the mass media and has, in turn, been picked up by an array of 'right thinking' people who, like Kit Malthouse the Mayor of London's adviser on crime and policing, has in effect declared outright war on what he defines as the problem of snarling weapon dogs in London'5.

There is a new weapon of intimidation terrorising the streets of London. Using a weapon dog is no different to using a gun or a knife to attack, maim and even kill. More and more people are choosing specific types of breeds as their weapon of choice and choosing them for a reason. Certain types of dogs are inherently more aggressive than others. At the top of the list are bull breeds, developed for one purpose: to attack and fight. It is no longer valid to look solely for solutions which rely on

\footnotetext{
${ }^{5}$ In a further statement Malthouse argued that 'weapon dog owners should face knife crime jail terms' (Watts 2010). Writing in the Times Malthouse went so far as to say 'we should be bolder about removing all status dogs from circulation altogether. Taken at face value this means the end of all bull dog breeds in the UK. Despite the fervor of his crusade there has been a noticeable absence of public support for this dog killing fanatic.
} 
responsible ownership; there is something in the dogs which must be considered (Malthouse 2009)

In response to what has been considered a serious escalation in the dangerous dog situation in the UK, the British police have returned to enforcing the conditions of the Act. The police have also developed new initiatives to confront the perceived problem. In the case of the Metropolitan Police Service in London, this has involved creating the Status Dogs Unit, an organisation populated by a group of police officers with a mandate to seize and destroy Pit Bulls along with other so called 'status dogs' (in practice Bull Terrier breeds owned by working class people). Since its inception this unit has seized over 1,000 dogs which have been kept at an annual cost to the taxpayer of $£ 3$ million (Greenwood 2010)6.

In the face of spiralling operational costs, largely attributable to the Status Dogs Unit, the Metropolitan Police Authority (MPA) requested £10.6 million in 2010 for kennelling and care costs for the dogs involved. Far from questioning whether the escalating costs to the public was justified by the evidence, Lord Toby Harris, the former chair of the police committee which deliberated the request responded by saying 'Why should we kennel these animals in the first place, why don't we just put them down' and subsequently 'why don't we kill them when they are seized' (Endangered dogs.com 2010). Meanwhile, the police in Liverpool introduced a new front in the war against dogs by taking the expedient step of introducing 'dog amnesties' on the working class estates where Pit Bulls were likely to be found. The amnesty however, was not for the dog but for the owner who the police undertook not to prosecute if they agreed to hand over their pets - which were then summarily executed (BBC, 2007).

\section{Evidence?}

For the supporters of breed specific legislation the Dangerous Dogs Act was passed on the basis that the UK was facing a novel threat from a dog that was in some terrible way essentially different in temperament and aggression than other dogs. In a rigorous attempt to find out if there was any truth to claims that Pit Bulls 'invariably go mad' and 'bite differently' to other dogs, Kaspersson (2008) recently reviewed the epidemiological literature on dog bites and found that dogs like Pit Bulls were certainly dangerous, but their bite was no more dangerous than many legal breeds such as the Rottweiler and German Shepherd. Pit Bulls did not bite the most and nor were they the most aggressive of dogs. She concludes:

The answer to the question whether 'dangerous breeds' bite at a rate justifying singling them out for breed-specific legislation is therefore 'no.' 'Dangerous breeds' do not bite at significantly higher rates and their singling out for bans is therefore not justified. Instead, there are adverse effects of breed-specific legislation as it gives the illusion of tackling a problem, when it in practice only addresses a limited number of symptoms (Kaspersson 2008: 219). 
While fatal dog attacks make headline news, the reason they do so is that such attacks are very rare. Since 2005, nine (human) dog bite fatalities have occurred in the UK, with 12 dogs involved, an annual rate of almost two people killed. Hardly significant when you consider that over 20 people are killed each year by horses and over 3,000 annually by cars (O' Neill, 2007). Fatal attacks on humans invariably occur in homes, where the dog involved was most often a family pet (see Kaspersson forthcoming). Fatalities have not occurred in public places where groups like the gangs supposedly using these dogs are typically found. It is worth noting that Pit Bulls were involved in only two of the cases where a fatality has occurred, legal breeds were implicated in the rest. In all of these cases the dogs had been neglected or abused by their owners, allowed inappropriate unsupervised access to small children, or left in the control of incompetent adults. The dog is often the victim of inhumane treatment; yet, the dog is always blamed and killed. Unfortunately, these rare cases are also used as an excuse to target the breed, in what Delise appropriately terms 'the Pit Bull placebo' (Delise, 2007): in other words, 'a dog bites so lets kill them all and things will be better'.

While accusations continue to be made about the rise of 'status dogs' and the use of such dogs by gangs, what is noticeable is that there is no compelling evidence ever cited to support the claims made. Let us consider some examples. In the words of a recent RSPCA briefing paper on the problem of 'weapon dogs':

Dangerous dogs are widely used by gangs and criminals to intimidate and cause injury to other people and also some animals. The possession of them is often closely associated with other worrying elements of ASB and gang culture, including knife violence and drugs (RSPCA 2010).

Similarly in the publication 'Weapon dogs: The situation in London' produced by the Greater London Authority we are told:

There is no doubt that a proportion of Pit Bulls and other 'weapon dogs' are being deliberately trained to attack people and for dog fighting (Monks, 2009).

Evidence to support these claims, like Macavity the mystery cat, is never present when you look for it. The RSPCA paper provides no evidence at all to justify the claims it makes. All we are left with is assertion ${ }^{7}$. The GLA report presents information regarding police and RSPCA activity pertaining to dog related cases, but activity alone cannot be taken as evidence of wider trends in dog related incidents. For example, we are told in the GLA report that 'the number of dogs

\footnotetext{
${ }^{7}$ I contacted the RSPCA in 2010 and asked them for their evidence. I was told that the gang connection was very clear and that they were now breeding 'bad Pits'. These are apparently dogs bred to be human aggressive (Pit Bulls, it could be noted are bred to be human friendly, an essential trait in breeds bred for dog fighting). The women I spoke to also claimed the bites of these dogs were far worse than that of any other dog. When I pointed out that these 'facts' were not supported by the epidemiological literature on dog bites she claimed 'we don't need research to tell us how dangerous these dogs are'. When I asked her where her facts came from she replied 'Pit Bull experts'. These included the head of the MPS Status Dog Unit and an ex member of the unit - in other words, people with a vested interest in Pit Bull seizure and killing.
} 
seized by the MPS has increased 44\% between 2007 and 2009', this is considered as evidence of a growing problem with 'dangerous dogs'. As the reasons for this growth has much to do with policy changes (i.e. the decision to create a specialist unit with a mandate to seize dogs and a policy shift to seize more dogs as opposed to fewer), it may be as much the police response to rising concerns about 'dangerous' dogs, than changes in dog ownership or gang behaviour, that explains the extent of the 'dangerous dogs' problem.

The only other evidence supplied is of the anecdotal form, and as such, cannot be treated as credible. For example, in the GLA report we are informed that:

anecdotal evidence suggests that many residents do not want to leave their houses or make use of their local parks because of the intimidation and threats posed by dangerous and aggressive dogs and irresponsible owners (Monk 2009).

Or quotes such as this reported by the BBC:

It is well known, anecdotally, that there is an increasing problem of dogs being used like this, as 'tools' of crime, or in the commission of crime. We have spoken to the RSPCA, Metropolitan Police Authority, dog warders and vets, who all back this up (BBC, 2006) .

What is actually occurring here is a continual self referential feedback loop whereby various control agents, including the police, journalists, practitioners and politicians, end up quoting each other about a problem everyone takes for granted and which must be serious (because everyone keeps telling everyone else it is). By evoking a colourful inflated rhetoric about 'weapon dogs' it is easy to see how a sense of proportion can so easily be evicted. By failing to commission serious research that might fill in some of the information deficits, it is easy to see why fantasies about dangerous dogs come to prevail instead ${ }^{8}$.

So what is the nature of the threat posed by so called 'dangerous dogs' and what, if anything, has this to do with gangs? Without systematic research it is difficult to answer this question. If we apply common sense to the available evidence then the picture that emerges is rather different from the alarmist headlines the public typically receive.

At first sight it might appear that the relationship between 'dangerous dogs' and gangs is very real given the widely reported gang related violent incident in London in $2009^{9}$. In this case a dog was used to attack two people, one of whom received a number of dog bites. It was human inflicted stab wounds, however, that were ultimately responsible for the victim's death. While this case attests to a gang connection, it was also reported that this was the first

\footnotetext{
8 In this respect it will be interesting to see if the research that the RSPCA have recently commissioned from Cardiff University might make a difference to the low quality public debate about so called 'dangerous dogs' that has laregely prevailed.

9 To gain some sense of the sensational way this case was reported see Cahalan (2008) and Metropolitan Police (2010).
} 
case of this kind, which is also why it received so much media attention. This case alone certainly should not be used to reduce the problems posed by 'dangerous dogs', to a question of gangs, or to establish that 'gangs are now using weapon dogs' to 'solve their conflicts' in the UK today, as claimed by the RSPCA.

While many gang-affiliated men may own or aspire to own 'status dogs' like Pit Bulls and Staffordshire Terriers, many other young people in working class estates in the UK (including a number of young women) do as well. So do a number of adults (Kaspersson 2008). This suggests that these breeds are popular in working class areas (just as Whippets are popular among many northern communities). Many people want to own such dogs, not just gang members. The population of 'status dog' owners, in other words, is much wider than the gang ${ }^{10}$.

While Pit Bull ownership may occur because of the breeds associated 'hard' image (its extrinsic appeal), these dogs make devoted pets and are by nature very tractable with humans (their intrinsic appeal). Indeed, a significant number of young gang affiliated men interviewed in recent research by Maher and Pierpoint (see article herein) claimed that it was specifically the issue of companionship that defined their relationships to their dogs. Interestingly none of the dog 'experts' interviewed in this research made any reference to this relationship.

Rather than define the many real problems posed by dogs like Pit Bulls as a gang problem, a less sensational interpretation probably has greater explanatory power. The problem here is likely to be one posed less by innately psychotic dogs trained to attack humans on command by organised gangs settling their conflicts; the issue is more likely to be posed by young, immature owners of powerful dogs that are under exercised, badly trained, often neglected and which are not kept under effective control by their owners. While humans can certainly be intimidated and bitten by such dogs, the problem here is not 'gang dogs' but the irresponsible ownership of such dogs by a growing number of young people who consider them a fashion accessory.

Unfortunately, the problem with less sensational interventions such as this, is that they run the very real risk of being ignored in a world where sensational headlines and inflated rhetoric have far greater currency. By continually posing the many real problems posed by dog ownership in terms such as 'weapon dogs' so a discursive space is created where totally disproportionate responses come to appear justified, while more measured and responsible approaches to what remain real problems get sidelined. And so the dogs like Pit Bulls get seized and killed.

While criminals may use dogs, the context in which they do so varies. To begin with, they may use them to protect criminal property. In fact, the motive here is no different from that applied by legal businesses who also employ guard dogs to protect valuable goods. It could also be the case that the ownership of dogs like Pit Bulls occurs, not because of a desire to own a 'weapon dog' to 'terrorise a neighbourhood', but because it is part of the wider cultural fabric of the criminal fraternity. Like wearing branded clothing, it is something you do to affirm and elevate your status relative to others. It could be remarked that legal

\footnotetext{
${ }^{10}$ Surveys indicate that membership of gangs is typically between $5-8 \%$ of the populations sampled where most surveys are typically conducted in high crime areas or among high risk groups such as young offenders See Hallsworth and Young (2008).
} 
dogs like German Shepherds are better equipped with the instincts that allow them to be trained as human aggressive, rather than dog fighting breeds like Pit Bull Terriers which have historically been bred to be human friendly ${ }^{11}$.

Rather than invoke the organised gang to explain why Pit Bulls persist despite the State's attempt to kill them, more can be gained by looking at the wholesale failure of the Dangerous Dogs Act to achieve its stated purpose which was to kill the dogs and deter people from owning them. The problem with deterrence strategies however, as Kaspersson, (2009) (drawing upon the work of Mathieson (1990)), points out, is that deterrence only works if you are likely to be deterred. As many people continue to own banned breeds like Pit Bulls, a good case could be made for suggesting that this is not a population for whom deterrence appears to have worked. Indeed, by criminalising dogs like Pit Bulls, it is arguable that the Dangerous Dogs Act has paradoxically worked to enhance their reputation and increased their appeal to the very people the state is actively trying to discourage from owning them ${ }^{12}$. At the same time, in what has become a demand led economy for these dogs, the Act has created the preconditions for an illicit market that trades in these breeds.

\section{Why kill dogs?}

How can we explain the lurch towards dog killing which the UK has embraced? I would suggest the intersection of a number of factors. We can begin with the media. Media driven moral panics by their nature are fantasy production machines. As moral panic theory shows, they work to transform often innocuous incidents into events that provoke mass hysteria. Within them the atypical become normalised, the exception becomes the rule and what is small and often insignificant assumes momentous importance. The deviance amplification spiral that accompanied the discovery of the Pit Bull is testimony to the disproportionate power to define enemies that the mass media commands.

Britain is also a society whose State, in recent decades, has been transformed. What was once a Welfare State is withering whilst, ominously, a far more coercive Security State is evolving (Hallsworth and Lea 2011). Unlike the welfare state which sought to include its excluded margin, the security state may be defined as a formation that wages war against it. The disproportionate response to the rise of 'dangerous dogs' in this sense can be understood as a direct manifestation of the Security State and the punitive turn in which it is engaged. This is evidenced both by the exceptional and disproportionate nature of the response to the dogs which, as we saw, invoked pre-emptive criminalisation and the reversal in law of the burden of proof.

\footnotetext{
11 The reason for this is that in the context of a dog fighting arena it would be lethal to have aggressive dogs present which may attack the dog man or indeed the audience. It could be noted that the fact Bull Breeds like Pit Bulls are human friendly is not a fact typically discussed by the media.

12 In a recent paper Kaspersson compared the consequences of the Dangerous Dogs Act with the consequences of Sweden's attempt to ban the purchase of sexual services. The Dangerous Dogs Act failed for the reasons cited above which is derived from Kaspersson's argument. The Swedish Act however succeeded. In her attempt to explain this difference she argued that in the case of Sweden, many of the men who purchased sexual services were middle class and married and, as such, had a reputation and status to lose if they were prosecuted under the law. In other words deterrence worked for this constituency in ways it did not for Pit Bull owners. See Kaspersson. (2009).
} 
Once an industry of dog seizers and killers have been assembled, so in Nils Christie's terms, an industry is formed which has a vested interest in creating the preconditions for its own employment (Christie 2000). To put this another way, if you are paid to seize dogs like Pit bulls, then it pays to talk up the menace that these dogs allegedly pose in order to justify an ongoing flow of resources. Consider, for example, the Metropolitan Police Service Status Dogs Unit, it justifies its existence on the grounds that its officers are involved in the fight against organised criminal groups like gangs. On one hand this could be explained on the basis that seizing people's pets and picking up dogs who have bitten other dogs is low status work and by recasting this as the fight against organised crime it assumes a significance and status such activity otherwise lacks. But there is an industrial logic to this; by continually talking up the Pit Bull menace, the Unit continues to justify its employment and the huge resources needed to fund its murderous activity.

Working class men predominantly own Pit Bulls and this is also an important contributory factor in their destruction. Their owners were understood, indeed interpreted from the very beginning, through the gaze of underclass thinking which enjoyed wide circulation in the UK where it was being mediated by commentators like Charles Murray (Murray and American Enterprise Institute for Public Policy Research. 1999). He had singled out, in the 1980s, (to widespread media, not to say political, acclaim and acceptance) the explosive growth of what, evoking older Victorian terminology, he termed the 'unrespectable poor'. This section of the working class was not, he claimed, a product of poverty and exclusion; he considered it instead a feckless author of its own misfortune. They constituted, he suggested, a permissive criminal class who could only be confronted through an array of coercive measures that the right wing government of the day was quite happy to implement. Dog killing, in this sense, was part of the wider class war that was being fought at the time and Kenneth Baker was quite aware of this fact when in his biography he observes that his single aim was to rid the country of Pit Bulls, while not upsetting what he termed 'the green welly brigade': in other words middle class conservatives like himself (Baker 1993).

As Routine Activity Theory shows, crime occurs not only because offenders offend, but also because there is no capable guardian around to protect the victims (Felson 1994). With this in mind the lurch towards dog killing can also in part be explained by the fact that dogs like Pit Bulls lack capable guardians. The eugenically infatuated Kennel Club would not even accept the Pit Bull Terrier as a breed and, its middle class organisers did nothing to oppose the Dangerous Dogs Act whose target, after all, were dogs owned by a despised section of the working class. While condemning the Act today, it could be noted that the RSPCA did not oppose the Act when it was being framed. The RSPCA also continues to put out inflammatory rhetoric about Pit Bulls and has too intimate a relationship with police dog killing units. Far from protecting dogs it continues to cooperate with a State that continues to kill them.

Finally, the dog-killing spree can be understood as a direct expression of the disproportionate and unequal power relations that humans exercise over the animals in their care. Dogs in this sense might be sentient creatures, affectionate to humans, but their existence is only ever justified on the basis that they are means to our ends, not ends in and of themselves. They exist as they have always 
existed outside of the social contract (Sollund, 2008; Svard, 2008). They are secondary beings, creatures that cannot advocate for themselves. As animals with no rights, and as creatures wholly at the mercy of humans, the suspension of the Pit Bulls rights to breed and live was simply an extension of power relations that work to oppress non-humans everywhere (Beirne and South 2007). And it is this stark imbalance in power that explains how easy it would be to gain mass support for breed specific legislation based on a 'kill them all' philosophy.

\section{Conclusion}

In this paper I have tried to identify one class of harms that humans are involved with in relation to what is often referred to as Man's best friend. This study of the social response to the Pit Bull has sought to show how a society of 'animal lovers', without evidence, came to demonize a dog and second, create the means to slaughter it. Unfortunately such killing is still, shamefully, part of UK government policy even while the Dutch government recently repealed its own version of breed specific legislation on the basis it achieved nothing (Endangered dogs.com 2008). Sadly, the Dutch remain the exception, while the UK continues to act as a source of inspiration to a range of other societies who also want to exterminate the Pit Bull. Australia implemented the British Act without anyone actually being attacked by a Pit Bull. Several other 'civilized' European societies have also followed the UK's lead and introduced variations on the theme, including Germany, France, Denmark, Norway and Italy. The murder of the Pit Bull Terrier unfortunately looks set to continue, a sad reflection on the punitive societies in which we live.

\section{Bibliography}

Baker, K. (1993). The turbulent years: my life in politics. London: Faber and Faber.

Baker, K. (2007). "Why the law should bite back." The Guardian. 3 January. Accessed 07/11/2009.

Bull Dog Breeds.com (2010). The American Pit Bull Terrior. http://www.bulldogbreeds.com/americanpitbullterrier.html Accessed 11/02/2011.

BBC News. (2007). 'Amnesty nets seven illegal dogs' $B B C$ News http://news.bbc.co.uk/1/hi/england/merseyside/6340583.stm $\quad$ Accessed 11/02/10.

BBC News. (2006). 'Row over Dangerous dogs Unit' $B B C$ News http://news.bbc.co.uk/1/hi/england/london/7819138.stm Accessed12/11/10.

Beirne, P. \& South, N. (2007). Issues in green criminology: confronting harms against environments, humanity and other animals. Cullompton: Willan. 
Cahalan P. (2008). 'Dog gang admit terrifying school attack'. This is Local London. http://www.thisislocallondon.co.uk/news/topstories/3781805.WANDSWORTH Dog gang admit terrifying school attack/ Accessed 7/11/10.

Christie, N. (2000). Crime control as industry: towards gulags, Western style. Oslo London; New York: Scandinavian University Press; Routledge.

Cohen, S. (1972). Folk devils and moral panics: The creation of the Mods and Rockers. London: MacGibbon and Kee.

Delise, K. (2007). The Pit Bull Placebo: The Media, Myths and Politics of Canine Aggression. Anubis Publishing. www.fataldogattacks.com Accessed 7/11/10

Doward, J. (2007a). 'Police back new law on killer dogs', The Observer, 13 May.

Doward, J. (2007b). 'The "family pet" bred to be trained as vicious fighter', The Observer, 5 August.

Endangered dogs.com. (2010). Culling of Dogs Requested.

http://www.endangereddogs.com/MPAMeetingReport.htm Accessed 4/01/11.

Endangered dogs.com (2008) Netherland to repeal Breed Ban http://www.endangereddogs.com/EDDRNetherlandsBSL.htm Acessed $17 / 02 / 11$

Felson, M. (1994). Crime and everyday life: insights and implications for society. Thousand Oaks, Calif: Pine Forge Press.

Fitzgibbon, D. W. (2004). Pre- emptive Criminalisation; Risk Control And Alternative Futures; London NAPO Monograph.

Goode, E. \& Ben-Yehuda, N. (1994). Moral panics : the social construction of deviance. Oxford; Cambridge: Mass, Blackwell.

Greenwood, C. (2010). 'Police Unit Takes 1000 dogs off the street'. The Independent. http://www.independent.co.uk/news/uk/crime/police-unit-takes1000-dangerous-dogs-off-the-street-1918659.html. Accessed 20/11/10.

Hallsworth, S., Ed. (2011). Gangland Britain: Realites, fantasies and industry. In B. Goldson. (Ed). Youth in crisis: Gangs terratory and violence. London, Routledge.

Hallsworth, S. \& Lea, J. (forthcoming). "Reconstructing Leviathon: contours of the emerging security state." Theoretical criminology.

Hallsworth, S. \& Young, T. (2008). "Gang Talk and Gang Talkers: A Critique". Crime, Media, Culture. 4(2):175-195.

Jones, S. (2006). Criminology. Third edition, Oxford: Oxford University Press. 
Kaspersson, M. (2008). On treating the symptoms and not the causes: Relections on the Dangerous Dogs Act. Papers from the British Criminology conference 2008, Vol. 8. http://www.britsoccrim.org/volume8/BCCvol82008.pdf

Kaspersson, M. (2009). When deterrence works - and when it doesn't: a comparison of Sweden's prostitution law and UK's Dangerous Dogs Act'. School of Humanities and Social Sciences Research Conference. (unpublished). University of Grenwich.

Kaspersson, M. (Forthcoming). What a difference a context makes.

Legislation.gov.uk. (1991). Dangerous dogs Act.

http://www.legislation.gov.uk/ukpga/1991/65/contents Accessed 20/01/11

Legislation.gov.uk. (1997). Dangerous dogs Amendment Act 1997. http://www.legislation.gov.uk/ukpga/1997/53/contents Accessed 20/01/11.

Lodge, D. (2010). "Barking mad? Risk regulation and the control of dangerous dogs in Germany". German Politics. 10(3): 65-82.

Malthouse, K. (2009). "Muzzles are not enough: dogs are weapons". The Times. http://www.timesonline.co.uk/tol/comment/columnists/guest contributors/ar ticle6898663.ece Accessed 8/9/10.

May, N. (2001). The Dangerous Dogs Act. http://www.staffordmall.com/bslthedangerousdogsact.htm Accessed 11/11/2009.

Metropolitan Police Service. (2010). Man who ordered dog attack on boy is found guilty of murder. MPS.

http://cms.met.police.uk/news/convictions/man who ordered dog attack on b oy is found guilty of murder Accessed 20/11/10.

Monks S. (2009). Weapon dogs: The situation in London. Greater London Authority.

Murray, C. A. \& American Enterprise Institute for Public Policy Research. (1999). The underclass revisited. Washington, D.C.: AEI Press.

O’Neill, B. (2007) 'Canine communities', The Guardian, 11 September.

Podberscek, A. (1994). "Dog on a Tightrope: The Position of the Dog in British Society as Influenced by Press Reports on Dog Attacks " Anthrozoos. 7(4): 232241.

Royal Society for the Prevention of Cruelty to Animals. (2010). Briefing Note on Dangerous Dogs.

http://www.politicalanimal.org.uk/assets/files/NewDangerous $\% 20 \mathrm{dogs} \% 20 \mathrm{bri}$ ef\%2004.03.10.pdf Accessed 8/10/10. 
Sollund, R. (2008). Causes for speciesism: Difference, distance and denial. In R. Sollund. (Ed), Global harms. Speciesism and ecological crime. New York: Nova pp 109-130.

Stephenson, S. (2008). "The dog that could not bark”. In R. Sollund. (Ed), Global harms. Speciesism and ecological crime. New York: Nova pp 151-166.

Svard, P. A. (2008). Protecting the animals? An abolitionist critique of animal welfarism. In R. Sollund. (Ed), Global harms. Speciesism and ecological crime. New York: Nova pp 167-186.

Watts, M. (2010). "Weapon dog owners should face knife crime jail terms". This is Local London. http://www.thisislocallondon.co.uk/news/8364924 ._Weapon_dog_owners_should_face_knife_crime_ja. Accessed 10/01/11. 